\title{
Processo de trabalho e relevância futura da crítica ao capitalismo
}

Benedito Rodrigues de Moraes Neto ${ }^{1}$

\section{Resumo:}

Este artigo se inicia com a explicitação de um equívoco teórico que marcou a análise crítica do capitalismo nos anos 60/70 do século XX, a chamada "crítica às forças produtivas", que utilizava o taylorismo-fordismo para ilustrar suas observações. Em seguida, procura-se mostrar a assustadora contemporaneidade desse equívoco, utilizando como exemplificação três textos do autor de extração marxista David Spencer. Finalmente, sugere-se que a análise crítica do processo capitalista de trabalho seja encaminhada para o terreno verdadeiramente promissor, fortemente amarrado às características atuais e prospectivas do trabalho. Essa sugestão parte da consideração de que, se o avanço recente das forças produtivas matou o taylorismo-fordismo, a crítica ao regime do capital precisa matá-lo também.

Palavras-chave: Forças produtivas; taylorismo; fordismo; processo de trabalho.

\section{Labour process and the future relevance of criticism to the Capitalism}

\begin{abstract}
:
This article begins with the explication of a theoretical misconception that marked the critical analysis of capitalism in the $60 \mathrm{~s} / 70 \mathrm{~s}$ of the twentieth century, the so-called "criticism of productive forces", which used Taylorism-Fordism to illustrate its observations. Next, we try to show the frightening contemporaneity of this misconception, using as an illustration three texts by the Marxist David Spencer. Finally, it is suggested that the critical analysis of the capitalist labor process must be routed to the truly promising terrain, strongly tied to the current characteristics and prospective of labor. This suggestion comes from the consideration that if the recent advance of productive forces has killed Taylorism-Fordism, criticism of the regime of capital must kill it too.
\end{abstract}

Key words: Productive forces; Taylorism; Fordism; labor process.

1 Livre-docente, professor aposentado da Universidade Estadual Paulista (UnespAraraquara). E-mail: brmneto@gmail.com. Revisão ortográfico-gramatical de Vânia Noeli Ferreira de Assunção. 
A humanidade só se propõe as tarefas que pode resolver.

K. Marx

\section{1- A “crítica às forças produtivas" e o taylorismo-fordismo}

No terceiro capítulo de nosso livro Marx, Taylor, Ford: as forças produtivas em discussão procuramos esclarecer como uma equivocada visão teórica sobre o fenômeno produtivo do taylorismo-fordismo permitiu reforçar, com ilustrações concretas, uma também equivocada visão teórica sobre a relação entre o capitalismo e a tecnologia, consubstanciada na chamada "crítica às forças produtivas". Procuraremos aqui resumir a argumentação ali apresentada. Um pressuposto fundamental é que se conceba o taylorismo-fordismo da forma que nos parece correta, coisa que pode ser extraída das seguintes colocações:

Quem estuda o taylorismo observa que, no fundo, o que Taylor tenta fazer é transformar novamente o homem num instrumento de produção, analogamente ao que se havia tentado na fase pré-maquinaria. Essa visão do homem como instrumento de produção magnifica-se no fordismo. Ao encetar sua típica inovação, que é a linha de montagem, Ford não fez outra coisa senão coletivizar o taylorismo, com o recurso fundamental da esteira, que procura resolver o problema tipicamente manufatureiro do transporte. $\mathrm{Na}$ verdade, esta grande fábrica fordista, ao invés de significar a indústria por excelência, a forma mais avançada da produção capitalista, significou, isto sim, uma 'reinvenção da manufatura', uma coisa extremamente atrasada do ponto de vista conceitual, a despeito de seu imenso sucesso do ponto de vista econômico, produtivo. A colocação de milhares de trabalhadores, uns ao lado dos outros, fazendo movimentos parciais, de forma alguma ajustase à noção marxista de produção à base de maquinaria. (MORAES NETO, 2003, p. 124)

Esta não é, todavia, a opinião de autores tão relevantes para a conformação da teoria marxista do processo de trabalho no século $\mathrm{XX}$ como Benjamin Coriat e Harry Braverman:

Tudo o que Marx anuncia em relação às características especificamente capitalistas do processo de trabalho (parcelamento de tarefas, incorporação do saber técnico no maquinismo, caráter despótico da direção) o realiza Taylor, ou mais exatamente, lhe dá uma extensão que até então não havia tido. (CORIAT, 1976, p. 22)

Torna-se necessário um completo e pormenorizado esboço dos princípios do taylorismo ao nosso histórico, não pelo que ele é popularmente conhecido - cronômetro, aceleramento etc. mas porque, além dessas trivialidades, reside uma teoria que nada mais é que a explícita verbalização do modo capitalista de produção. (BRAVERMAN, 1977, p. 83) 
Essa posição teórica que considera o taylorismo (e consequentemente o taylorismo-fordismo) manifestação por excelência da forma mais desenvolvida possível da produção capitalista autoriza utilizálo como ilustração da ligação entre tecnologia e capitalismo. Uma teoria que teve muita presença nos anos 60/70 do século XX, autodenominada "crítica das forças produtivas", efetuou exatamente esse movimento teórico. Vejamos inicialmente suas colocações críticas:

O fundo da questão é que, para reproduzir-se, a empresa capitalista tem necessidade não só de renovar seu equipamento, senão de que o novo equipamento posto em circulação por ela possua características tais que reproduza constantemente as bases técnicas da dominação do processo de trabalho. A hipótese subjacente é que a "técnica" capitalista é ao mesmo tempo técnica de produção e técnica de dominação (...). Consideradas em seu duplo aspecto de métodos de organização do trabalho e de "coisas" (meios de produção), as forças produtivas levam a marca das relações sociais nas quais estão inscritas e nas quais foram produzidas. (...) Cremos com A. D. Magaline que convém falar de um processo de materialização das relações de produção nas forças produtivas. (...) A verdadeira e única questão é que no capitalismo as forças produtivas são forças produtivas de e do capital. (...) haverá que decidir-se a admitir que a "base material" legada pelo capitalismo tem muitas possibilidades de mostrar-se totalmente inadequada para a instauração de relações de tipo socialista. (CORIAT, 1976, pp. 81-6)

(...) toda a tentativa para revolucionar as relações de produção exige uma mudança radical e simultânea dos meios e técnicas de produção (e não apenas da finalidade da sua utilização), porque a conservação destas faria ressurgir aquelas através da divisão capitalista do trabalho (GORZ, 1974, p. 172).

No mencionado capítulo de nosso livro, fizemos uma crítica a essa crítica, que pode ser assim resumida:

A consequência inevitável dos argumentos expostos é a extinção da contradição dentro do capitalismo. Ora, se a base material, o desenvolvimento e a socialização das forças produtivas promovidas pelo capitalismo são, por sua própria natureza material, eternamente capitalistas, o que explica a superação desse modo de produção? (MORAES NETO, 1989, p. 109)

Também procuramos mostrar, no mesmo capítulo, por meio de colocações de Benjamin Coriat e André Gorz, que a "crítica das forças produtivas capitalistas" sempre ilustrava suas posições com as linhas de montagem, manifestação por excelência do taylorismo-fordismo. Jamais as ilustrava com a maquinaria, com a produção automatizada, a forma mais avançada da produção capitalista. Vejamos o uso recorrente do taylorismo-fordismo como ilustração: 
Estes dois tipos de organização do trabalho (trabalho a peça, em máquina individual, e trabalho em cadeia) têm um traço em comum: a predeterminação "científica" dos tempos necessários à execução de uma tarefa repetitiva: a duração de cada gesto é estabelecida à escala do décimo e até do centésimo de segundo, sendo fixado um tempo-padrão para a execução de uma sucessão de gestos. (...) o parcelamento infinitesimal das tarefas não é consequência de uma tecnologia que hipoteticamente tivesse evoluído segundo as suas leis próprias independentes do contexto político-social. É antes consequência de uma tecnologia concebida para servir de arma na luta de classes (...). A organização "científica" do trabalho é, antes de mais nada, a destruição científica de qualquer possibilidade de controle operário. (GORZ, 1974, pp. 187-8)

As características "técnicas" dos meios de produção deverão, portanto, ser concebidas, antes de tudo e sobretudo, em função deste fato central na produção capitalista de mercadorias: a extorsão de mais-valia. A melhor ilustração desse ponto de vista é propiciada, sem dúvida, pela colocação em prática de linhas de montagem, isto é, da cadeia, por Ford, nos anos 20. (...) Queremos demonstrar que, desde seu nascimento, (a cadeia) responde, antes de tudo e sobretudo, à necessidade de permitir a maior extração possível de mais-valia, em um momento determinado da correlação de forças entre capitalistas e assalariados. (...) Também Macciocchi, de volta da China, constatava que: “(...) é impossível falar só de forças produtivas em geral. Levam impressas em seu seio a marca das relações de produção". O caso da cadeia de montagem, de que já falamos, ilustra isto perfeitamente. (CORIAT, 1976, pp. 76-85)

Conforme queríamos demonstrar, a visão equivocada do taylorismo-fordismo permitiu reforçar, ilustrando concretamente, a visão equivocada da "crítica das forças produtivas". O taylorismo-fordismo merece integralmente a crítica recebida. O problema é tomá-lo como ilustração por excelência da forma capitalista de organizar o processo de trabalho. Nosso passo seguinte é voltado à explicitação de um fato surpreendente: a contemporaneidade dessa posição no interior da teoria crítica do processo de trabalho capitalista.

\section{2- Ilustrando a contemporaneidade do equívoco: crítica à análise crítica de David Spencer sobre capitalismo e processo de trabalho}

Procuraremos, por meio da análise de três textos, um deles bastante recente, de um autor representativo da reflexão marxista contemporânea sobre processo de trabalho, David Spencer ${ }^{2}$ mostrar que nossas críticas

${ }^{2}$ São os seguintes os textos analisados: Braverman and the contribution of labour process analysis to the critique of capitalist production, de 2000; The Marxian view of work, de 
expostas no item anterior continuam extremamente atuais. Esse fato tem importante repercussão, pois nos encontramos em momento histórico de grande desafio teórico e político, em função do ritmo intenso da mudança tecnológica, com impactos profundos sobre o trabalho humano. Tentaremos argumentar que a prisão a uma visão equivocada da natureza das forças produtivas capitalistas empobrece sobremaneira a crítica ao capitalismo neste momento histórico crucial.

No primeiro texto (Braverman and the contribution...), Spencer se preocupa exclusivamente em marcar a importância teórica e política da obra Trabalho e capital monopolista, de Harry Braverman, publicada em 1974, assumindo a existência de uma unidade absoluta entre Braverman e Marx, tão absoluta que é tratada como um pressuposto, como algo que não precisa sequer ser justificado. Tanto assim que não há uma palavra sobre a análise do processo de trabalho em Marx (os Grundrisse não entram nem nas referências bibliográficas). Marx está inteiramente em Braverman. Segundo o autor, "Braverman, em poucas palavras, restabeleceu a crítica de Marx ao capitalismo” (SPENCER, 2000, pp. 224-5). A análise feita por Braverman sobre o processo de trabalho capitalista possuiria fortes desdobramentos políticos, reforçando sua unidade com Marx: "(Braverman) identificou as tendências à desqualificação com o imperativo capitalista da acumulação no sentido de promover a questão da mudança revolucionária" (SPENCER, 2000, p. 223). Vemos que a "tendência à desqualificação" é fundamental para toda a análise, e é importante notar que essa "tendência" não é procurada e problematizada dentro da análise histórico-teórica de Marx, mas sim procurada (e encontrada) dentro do taylorismo-fordismo no século XX:

Se os capitalistas necessitam preencher sua função de gerenciamento no local de trabalho, eles precisam buscar a minimização da contribuição cognitiva e técnica de sua força de trabalho para o processo produtivo. Durante o século XX, os capitalistas abraçaram a gerência científica, e a "revolução tecno-científica" associada, em seus esforços para separar o trabalho mental do trabalho manual. O controle conceitual da produção mudou para o capitalista, solapando as fontes tradicionais da resistência do trabalhador, baseada na qualificação e no conhecimento. (SPENCER, 2000, p. 225)

Vemos claramente que Marx não só está inteiramente em Braverman; ele só passou a existir com Braverman. No momento teórico fundamental constituído pelo processo de trabalho, Marx nunca existiu; toda sua reflexão era uma antevisão, coisa que só se materializaria historicamente com a emergência do taylorismo-fordismo, ou seja, em

2009; e Work in and beyond the second machine age: the politics of production and digital technologies, de 2016. 
Braverman, autor inteiramente prisioneiro do taylorismo-fordismo. Sobre a relação entre Marx e Taylor, Spencer comunga inteiramente da opinião expressa por Benjamin Coriat em 1976, já citada aqui. Para Spencer, tudo antes de Taylor teria sido dominado por trabalho fortemente impregnado de natureza artesanal. Nesse ponto, ele compartilha totalmente a surpreendente posição de Robert Linhart, também em 1976;

Definiu-se o taylorismo nos Estados Unidos e na Europa Ocidental como uma gigantesca operação de expropriação do saber operário em proveito do capital. Mas para que haja expropriação é necessário que esse saber exista no proletariado industrial. E donde pode vir esse saber senão da incorporação, por vagas sucessivas, da pequena produção artesanal na manufatura e depois na grande indústria? Assim, o "companheiro" perpetua durante certo tempo no seio da grande produção capitalista parte da perícia e da ideologia do artífice independente. Até $o$ taylorismo, o patrão industrial "subcontratava", de fato, uma fração global do trabalho da oficina, que continuava organizada como uma pequena empresa autônoma sob a direção do contramestre-mestre. O taylorismo, como expropriação, toma toda a sua dimensão de ofensiva estratégica no plano social quando investe contra classes operárias poderosas, experimentadas, qualificadas, herdeiras de séculos de ofício, de corporações, de artesanato. (LINHART, 1977, pp. 107-8, grifos do autor)

Ao assumir inteiramente a propositura de Coriat e de Braverman de que o taylorismo-fordismo consubstancia o que há de mais característico e avançado no processo capitalista de trabalho, propositura inteiramente equivocada a nosso juízo, Spencer inocula suas observações finais desse equívoco teórico, observações estas ligadas à questão da superação do capitalismo. O autor já antecipara esse fato na ligação feita entre "tendência à desqualificação" e "mudança revolucionária", presente em citação anterior. Em primeiro lugar, é necessário validar inteiramente, para toda a produção capitalista, a tendência que Braverman extrai fundamentalmente do taylorismo-fordismo, a da generalização da desqualificação do trabalho:

A abstração real do trabalho alienado encontra sua expressão concreta nas tendências específicas de degradação e desqualificação do trabalho. (SPENCER, 2000, pp. 225-6)

As contradições e contrapressões criadas pela separação entre trabalho mental e trabalho manual não refutam a "lei (leia-se tendência) de desqualificação" enquanto tal; antes, indica seu movimento causal e sua dinâmica. (SPENCER, 2000, p. 227)

(A desqualificação caracteriza) uma importante tendência necessária sob o capitalismo. (SPENCER, 2000, p. 227)

Logo após assentar esse ponto, Spencer coloca dessa forma a questão da superação do capitalismo: 
Braverman identificou as tendências à desqualificação com a "abstração do trabalho". (...) A mensagem-chave de Braverman era de que isto (a emancipação do trabalho) não poderia ser alcançado sem a abolição das relações capitalistas de propriedade. (SPENCER, 2000, p. 233)

Vejamos então o esquema histórico-teórico de Spencer:

\begin{tabular}{|c|c|}
\hline CAPITALISMO & PÓS-CAPITALISMO \\
\hline Trabalho abstrato: & Transcendência do trabalho \\
degradação/desqualificação do trabalho & abstrato: emancipação do trabalho \\
\hline
\end{tabular}

Esse esquema histórico-teórico reaparecerá no próximo texto de Spencer a ser analisado (The Marxian view of work). No início desse capítulo de livro, Spencer trata de marcar a importância conferida por Marx ao trabalho na moldagem da vida humana:

Para Marx, o trabalho não era apenas uma atividade econômica realizada por razões extrínsecas. Era também uma atividade humana essencial que poderia ser uma fonte de desempenho criativo e autorrealização. (SPENCER, 2009, p. 47)

Marx visualizava a capacidade de participação num trabalho criativo como uma parte essencial da natureza humana. (SPENCER, 2009, p. 51)

(Os economistas clássicos) não perceberam o potencial do trabalho para se tornar uma atividade positiva e criativa através da remoção (eliminação) do capitalismo. (SPENCER, 2009, p. 47)

Fica claro que em Marx, na leitura de Spencer, o capitalismo proporciona o surgimento do potencial para o trabalho emancipado, que só se consubstanciaria após sua superação histórica. Para nós, na análise marxiana, esse potencial proporcionado pelo capitalismo está fundamentalmente ligado ao desenvolvimento das forças produtivas, e caracteriza momento fundamental da natureza autocontraditória do capital. Todavia, na interpretação de Spencer, a autocontraditoriedade desaparece. Acreditamos que essa interpretação é tributária da visão estabelecida no texto anterior, segundo a qual "Marx está em Braverman". Ora, se "Marx está em Braverman", e Braverman está inteiramente impregnado de Taylor e Ford, então está anulada a autocontraditoriedade do capital, pois:

A contraditoriedade do capital consigo mesmo está posta por Marx a partir do movimento de negação do trabalho vivo como unidade fundamental do processo de produção, e sua substituição pelo trabalho morto. Sendo assim, como se coloca a natureza autocontraditória do capital quando sua base técnica possui a natureza taylorista/fordista? A resposta é: não se coloca; a forma taylorista/fordista de organizar o processo de trabalho não é contraditória com o capital enquanto relação 
social; pelo contrário, o taylorismo/fordismo chancela a forma social capitalista. Uma forma técnica lastreada no trabalho humano, que induz ao emprego de milhares de trabalhadores parciais/desqualificados, é perfeitamente assentada à forma social capitalista; o sonho da eternidade capitalista teria encontrado sua base técnica adequada. (MORAES NETO, 2003, pp. 60-1)

Vejamos como essa anulação da autocontraditoriedade se mostra no Marx de Spencer:

(Sob o capitalismo) o trabalho, ao invés de se constituir no fundamento do desenvolvimento humano, tornou-se um simples meio para a obtenção de um rendimento, e associou-se à labuta sem fim e ao trabalho enfadonho e fatigante (endless toil and drudgery). (SPENCER, 2009, p. 51)

Ora, se o trabalho sob o capitalismo assume necessariamente a forma de "endless toil and drudgery", então o mencionado "potencial" permanecerá sempre oculto. E não apenas oculto no sentido de estar presente e as pessoas não conseguirem perceber. Sequer está presente. No entanto, após a superação do capitalismo, o trabalho adquirirá seu caráter emancipador: "Marx argumentou no sentido da abolição do capitalismo a fim de restabelecer (o autor não esclarece de onde surge esse "restabelecer") o trabalho como uma atividade realizadora e livre." (SPENCER, 2009, p. 67) Verificamos então que se estabelece novamente, para Spencer, agora lastreado em Marx, o esquema histórico-teórico do texto anterior, inteiramente assentado em Braverman:

\begin{tabular}{|c|c|}
\hline CAPITALISMO & PÓS-CAPITALISMO \\
\hline $\begin{array}{c}\text { Trabalho empobrecedor (endless toil } \\
\text { and drudgery) }\end{array}$ & $\begin{array}{c}\text { Trabalho como atividade realizadora } \\
\text { e livre }\end{array}$ \\
\hline
\end{tabular}

Para o esquema histórico-teórico assumido nos dois textos de Spencer (ou seja, presentes, para ele, em Braverman e em Marx), vale colocar a seguinte questão crítica: como passar "daquilo" (trabalho empobrecido no capitalismo) para "isto" (trabalho enriquecido no póscapitalismo), se nada "disto" acontece no capitalismo, só "aquilo"? Teríamos de assumir a emergência histórica súbita de uma epifania social, uma revelação súbita de um futuro que nada tem que ver com o presente. E para que este futuro seja alcançado é preciso aniquilar o presente, que só tem a oferecer "endless toil and drudgery”. Não há dialética alguma aí, mas sim uma esquisita metafísica.

Essa necessidade de aniquilamento do presente, até agora manifestada na esfera do trabalho, irá também se revelar no terceiro texto (Work in and beyond...), agora na esfera da tecnologia. Há uma implícita amarração entre as duas esferas, ou seja, a tecnologia deve ser 
inteiramente aniquilada por ser toda ela causadora de "endless toil and drudgery”. Trata-se, na verdade, de uma reprodução perfeita da tese que criticamos em Marx, Taylor, Ford, e que apresentamos no início deste texto, qual seja, a da "crítica às forças produtivas capitalistas", agora aplicada às tecnologias digitais, que caracterizam o avanço tecnológico do atual momento histórico. As considerações de Spencer são realizadas como uma crítica às colocações de Brynjolfsson e McAfee no influente livro $A$ segunda era das máquinas. Vejamos as citações mais esclarecedoras:

Ao invés de ser alguma força neutra operando pelas costas das pessoas, as tecnologias digitais são fortemente conectadas com as relações de poder. Essas relações, de forma mais direta, influenciam a forma, a direção, e os resultados das tecnologias digitais, inclusive no interior do campo do trabalho. (SPENCER, 2016, p. 3)

(...) os autores não conseguem reconhecer como as tecnologias digitais são produtos de um poder desigual - elas não são neutras enquanto tais; ao invés disso, são criadas, preparadas e reproduzidas sob condições tais que o poder reside no capital, e não no trabalho. (SPENCER, 2016, p. 7)

$\mathrm{Na}$ medida em que as tecnologias digitais são usadas com o propósito da produção de mais-valia, elas levarão a resultados que são favoráveis aos empregadores capitalistas e desfavoráveis aos trabalhadores. As tecnologias digitais podem, e frequentemente o são, ser utilizadas para facilitar a exploração, e nesse sentido elas não necessariamente representam algo amigável aos trabalhadores. (SPENCER, 2016, pp. 7-8)

O ponto principal é que as tecnologias digitais não devem ser vistas em termos puramente técnicos e econômicos; ao invés disso, devem ser vistas como definidas política e socialmente. O capitalismo fornece à tecnologia digital uma forma particular. (SPENCER, 2016, p. 14)

Estamos de novo em presença da "crítica às forças produtivas capitalistas", de tanta força no pensamento crítico nos anos de grande influência maoísta. Para os pensadores dessa posição teórica dos anos 1960/70, se quiséssemos transitar da sociedade capitalista para uma sociedade pós-capitalista, teríamos de inventar novas máquinas, "amigáveis" aos trabalhadores. Agora, teríamos de inventar novas tecnologias digitais, o que inclui todas as máquinas que incorporam essas tecnologias, como robôs, por exemplo, também "amigáveis" aos trabalhadores. Interessante (e sintomático) é que, da mesma forma que observamos nos autores da "crítica às forças produtivas" dos anos 60 e 70 do século XX, quando se exemplificava a inoculação capitalista da tecnologia pelo taylorismo-fordismo, a ilustração de Spencer se dá pelo que chama de "taylorismo digital", cuja natureza tem que ver com o uso de sistemas digitais para reforçar o controle do trabalho humano pelo capital 
e ampliar sua intensidade. Nenhuma palavra sobre sistemas automáticos de manufatura, uso de robôs de forma geral, na indústria e no setor terciário, uso de inteligência artificial e outras dimensões mais atuais da tecnologia. É bastante desajustada a ideia subjacente de taylorização das atividades de trabalho bastante exigentes de qualificação e de capacidade inovativa, como é comum em segmentos produtivos mais avançados, como laboratórios e empresas de software, por exemplo.

A inoculação das forças produtivas pelas relações sociais capitalistas exige que, para transformar a sociedade, tenhamos de começar tudo de novo, inclusive repensando a máquina têxtil da primeira Revolução Industrial. Acho que não estaremos exagerando se chamarmos essa tese de "Marxo-Ludista". A noção fundamental da autocontraditoriedade desaparece totalmente.

Nos dois textos anteriores fica clara a dificuldade presente no raciocínio de Spencer: como os seres humanos podem transitar de uma sociedade capitalista para uma sociedade pós-capitalista se a primeira só oferece a todos "endless toil and drudgery"? De onde a humanidade poderia extrair a informação de que existiria um trabalho possível como atividade realizadora e livre? Por isso, em nossa crítica, imaginamos a necessidade de uma "epifania social”, do súbito surgimento da visão de um futuro que não tem nenhuma ligação com um presente a ser aniquilado. Nesse terceiro texto, a "epifania social", com aniquilamento do presente, é ainda mais exigente, pois toda a tecnologia desenvolvida ao longo da vigência do capitalismo deve ser destruída, e outra completamente diferente deverá ser inventada. Surge uma agravante, porém: a sociedade a ser aniquilada só se fortalece com o progresso tecnológico nela gerado, pois "as tecnologias digitais refletem e reforçam as relações sociais capitalistas” (SPENCER, 2016, p. 15).

Realmente não é possível entender as possibilidades de transformação: todo o trabalho e toda a tecnologia encontram-se inteiramente impregnados da perversidade da forma social capitalista; tudo tem de ser jogado fora, aniquilado; o futuro não surge do presente, mas sim de sua aniquilação; todavia, a sociedade que impregna tudo de sua perversidade imanente só se reforça ao progredir. Talvez percebendo o "beco sem saída" em que se colocou, Spencer realiza, de forma inteiramente ad hoc, as seguintes observações ao final do texto:

De forma radical, a mudança para um sistema de empresas de propriedade dos trabalhadores deve ser vista como a única maneira de a sociedade realizar plenamente os benefícios das tecnologias digitais. (SPENCER, 2016, p. 15)

Ora, quais são esses "benefícios" que não são realizados "plenamente" dentro do capitalismo? Eles existem, podem ser visualizados, ainda que parcialmente, dentro do sistema capitalista? Mas a 
tecnologia não estava inteiramente inoculada pela perversidade da forma social capitalista? O autor parece não ter percebido que a entrada inteiramente ad hoc desses benefícios destrói toda sua argumentação.

A observação final do autor vai também na direção inglória da fuga do "beco sem saída":

Apenas desfetichizando as tecnologias digitais - i.e., vendo-as em seu contexto político adequado - é possível observar as barreiras e as oportunidades para o human flourishing nas sociedades tecnologicamente avançadas de hoje e do futuro. (SPENCER, 2016, p. 15)

Ora, se toda a tecnologia contemporânea está inteiramente inoculada da perversidade do regime do capital, não há como identificar inicialmente as "oportunidades" e posteriormente as "barreiras"; toda a tecnologia tem é de ser inteiramente destruída para que uma nova sociedade possa brotar. A identificação de tais "barreiras e oportunidades" exige que se supere conceitualmente, de forma radical, a prisão ao MarxoLudismo.

\section{3- Identificando "oportunidades"}

Coloquemos inicialmente algumas citações representativas das principais transformações na estrutura do trabalho que ocorreram nos países de capitalismo desenvolvido a partir das duas últimas décadas do século XX, quando então conseguimos nos livrar da mediocridade taylorista-fordista:

As oportunidades de emprego irão crescer, mas o crescimento do emprego será maior nas ocupações de maior nível de qualificação, nas quais os computadores irão complementar o pensamento especializado e a comunicação complexa para produzir novos produtos e serviços. (LEVY; MURNANE, 2004, p. 93)

(...) o acréscimo na demanda relativa por trabalhadores qualificados está fortemente correlacionado com os avanços da tecnologia, particularmente as tecnologias digitais (BRYNJOLFSSON; MCAFEE, 2011, p. 41).

Como temos visto, as forças do crescimento econômico causam agora uma demanda crescente por trabalhadores altamente qualificados, enquanto reduzem a demanda por trabalhadores menos qualificados. (LEVY; MURNANE, 2004, p. 155)

(Exercer uma atividade de trabalho exigente de qualificação, impregnada de conteúdo) é a maior recompensa oferecida pelas economias mais avançadas. (PHELPS, 2008, p. 102)

Nossa consideração sobre os desdobramentos dessa evolução recente do trabalho já foi explicitada anteriormente:

O que nos interessa marcar aqui é que, para Marx, o desenvolvimento da sociedade humana exige que seja abolido 
todo o trabalho que não contribua decisivamente para a "autorrealização do indivíduo". Ora, como a "humanidade só se propõe as tarefas que pode resolver” (MARX, 1974, p. 136), dever-se-ia buscar, no interior do próprio capitalismo, em sua evolução histórica, o próprio encaminhamento da "abolição do trabalho" e da afirmação do trabalho como atividade, algo "atraente", "autorrealização do indivíduo". Ora, é exatamente isso que vem ocorrendo nos países de economia mais avançada, conforme nos revelam análises empíricas mais recentes. (...) Resta saber quais os desafios postos pela situação atual. Para o regime do capital, a pergunta seria: uma forma social fundada na produção mercantil com vistas à obtenção de lucro tem capacidade de proporcionar, de uma maneira geral, a conquista de um trabalho autorrealizador? A própria natureza da produção voltada para o lucro não dificultaria o processo por ela encetado de busca de um trabalho impregnado de sentido? (...) o que estamos querendo dizer é que o próprio regime do capital abre potencialidades, já vivenciadas, de uma vida mais rica, ligada a um trabalho "atraente", mas se transforma, ao mesmo tempo, num empecilho ao pleno desenvolvimento dessas potencialidades. Sendo assim, deparamo-nos com a ilustração histórica de uma noção marxiana de grande importância, a da contradição entre as forças produtivas e as relações de produção, amortecida durante a maior parte do século XX em função da forte presença da mediocridade taylorista-fordista. (MORAES NETO, 2014, pp. 96-7)

As pesquisas mais recentes sobre trabalho e tecnologia, algumas voltadas explicitamente à sondagem do futuro próximo, têm reforçado essa linha de argumentação. Vejamos algumas citações relevantes:

O impacto da computadorização sobre o mercado de trabalho está bem estabelecido na literatura, documentando o declínio do emprego em ocupações dotadas de elevado grau de rotina, isto é, ocupações consistentes principalmente de tarefas que seguem procedimentos bem definidos, que podem facilmente ser executados por algoritmos sofisticados. (FREY; OSBORNE, 2013, p. 2)

(...) as tarefas manuais das ocupações em serviços são menos suscetíveis de computadorização, na medida em que requerem um maior grau de flexibilidade e adaptabilidade física. (...) a tendência corrente se dá no sentido da polarização do mercado de trabalho, com emprego crescente em empregos cognitivos de rendimento elevado e ocupações manuais de baixo rendimento, acompanhada de um esvaziamento dos trabalhos rotineiros de renda média (FREY; OSBORNE, 2013, p. 3).

Essa bastante conhecida tendência do progresso tecnológico de nosso tempo de levar à polarização, com fortalecimento das ocupações nos dois extremos da estrutura ocupacional e esvaziamento da camada intermediária, será posta em xeque pelos futuros desenvolvimentos da tecnologia digital: 
Historicamente, a computadorização tem sido amplamente confinada às tarefas rotineiras, sejam manuais ou cognitivas, que envolvem atividades baseadas em regras explícitas. Em função dos avanços tecnológicos recentes, todavia, a computadorização está agora se espalhando em direção a domínios comumente definidos como não rotineiros. (FREY; OSBORNE, 2013, p. 15)

À medida que os custos dos robôs caem e as capacitações tecnológicas se expandem, pode-se esperar que os robôs substituam gradativamente os trabalhadores numa ampla gama de ocupações de baixo salário nos serviços (...). Isto significa que muitos dos empregos manuais de baixo salário, que previamente haviam sido protegidos da computadorização, podem diminuir ao longo do tempo. (FREY; OSBORNE, 2013, p. 22)

O estudo que estamos citando de Carl Frey e Michael Osborne, de 2013, que teve grande impacto na literatura sobre trabalho e tecnologia, coloca dessa forma suas principais conclusões:

De acordo com nossa estimativa, $47 \%$ do total de emprego nos Estados Unidos apresentam elevado risco de computadorização, significando que ocupações associadas são potencialmente automatizáveis daqui a um número não especificável de anos, talvez uma década ou duas. (FREY; OSBORNE, 2013, p. 38)

A computadorização das ocupações na produção simplesmente sugere a continuidade de uma tendência que tem sido observada ao longo das últimas décadas, com os robôs industriais assumindo as tarefas rotineiras da maioria dos trabalhadores da manufatura. À medida que os robôs industriais estão se tornando mais avançados, com sentidos e destreza incrementados, eles estarão aptos a exercer um leque mais amplo de atividades manuais não-rotineiras. (FREY; OSBORNE, 2013, p. 38)

A tabela 4 revela que ambos, salários e nível de educação, exibem uma forte relação negativa com a probabilidade de computadorização. Nós observamos que essa predição implica suspender a tendência corrente no sentido de uma polarização do mercado de trabalho (...). Ao invés da redução da demanda por ocupações de média renda, que tem sido o padrão ao longo das últimas décadas, nosso modelo prediz que a computadorização principalmente substituirá os empregos de baixa qualificação e baixos salários no futuro próximo. Em contraste, ocupações de elevada qualificação e elevado salário são os menos suscetíveis de computadorização. (FREY; OSBORNE, 2013, p. 42)

Nossas descobertas implicam, portanto, que, à medida que a tecnologia avança, os trabalhadores de menor qualificação serão realocados para tarefas que não sejam suscetíveis de computadorização, i.e., tarefas que requerem criatividade e inteligência social. Para que os trabalhadores vençam essa 
corrida, terão de adquirir criatividade e habilidades sociais. (FREY; OSBORNE, 2013, p. 45)

As observações finais de Frey e Osborne corroboram a recomendação de empregabilidade futura feita por Brynjolfsson e McAfee no livro já mencionado: "Nossas recomendações sobre como as pessoas podem continuar sendo trabalhadores de conhecimentos valiosos na nova era das máquinas são diretas: trabalhe para melhorar as habilidades de ideação, reconhecimento de padrões de amplo escopo e comunicação complexa." (BRYNJOLFSSON; MCAFEE, 2015, pp. 219-20)

Parece-nos bastante claro que as pesquisas empíricas e os estudos prospectivos não corroboram a visão Marxo-Ludista. Antes pelo contrário, o que se observa é o surgimento extremamente significativo das "oportunidades" (que surgiram ad hoc em Spencer). Desaparece, então, a "epifania social". A evolução do modo de produção capitalista, pelo incessante desenvolvimento das forças produtivas, recentemente revigorado pela microeletrônica, permite à humanidade se informar concretamente sobre a possibilidade efetiva de existência de um trabalho impregnado de conteúdo, desenvolvedor das individualidades. A construção do futuro implica transformar essa possibilidade já visualizada dentro do capitalismo em efetividade. Para lembrarmos de novo a ideia de Marx em epígrafe, a humanidade já pode resolver essa tarefa. Para isso, é necessário identificar as "barreiras" (que também surgiram ad hoc em Spencer), que impedem que a possibilidade se transforme em efetividade. Não é necessário, portanto, aniquilar o presente, mas sim superá-lo.

\section{4- A superação da "epifania social"; o capitalismo como etapa histórica fundamental de aprendizagem}

Esse último item tem a intenção apenas de deixar marcada uma linha crítica de investigação e de intervenção política ajustada ao presente, e muito especialmente ao futuro próximo do capitalismo. A questão que nos parece pertinente é: quais os limites que a forma social capitalista coloca para que o trabalho potencialmente realizador e livre se torne efetivo? Para isto, precisamos perscrutar a natureza do trabalho impregnado de conteúdo quando submetido às relações capitalistas de produção. Uma boa ilustração deste percurso nos é fornecida por Brendan Stone em seu artigo Will the "knowledge economy" save us?, de 2013, que se debruça sobre a natureza do trabalho em locais intensivos em conhecimento (knowledge workplaces), definidos como "locais de trabalho nos quais aos empregados não-taylorizados é fornecida relativa autonomia para buscar a realização de tarefas que envolvem conhecimento tácito ou codificado, além de criatividade, frequentemente da concepção até a execução" (STONE, 2013, p. 2). Vejamos as principais observações: 
A estrutura oferecida pelos estudos de Hunt e Kunda sugere que os trabalhadores não necessariamente trabalham de forma intensa, dedicando longas horas à companhia, porque assim o querem, mas porque necessitam fazê-lo por duas razões: eles estão inseguros, e caíram sob o controle normativo da companhia. Uma análise dos locais de trabalho intensivos em conhecimento sugere que o conflito entre os desejos dos trabalhadores e sua carga de trabalho dentro da dinâmica capital-trabalho leva à alienação do trabalho no sentido tradicional, e também à alienação de suas emoções e criatividade. (STONE, 2013, p. 7)

O potencial de alienação no local de trabalho intensivo em criatividade permanece existente porque os trabalhadores "criativos" permanecem trabalhadores, dependentes de um capitalista para a obtenção de salários, e subordinados a uma estrutura de gerenciamento. Seja forte ou não o controle da gerência, ao final, os empregados estão trabalhando para satisfazer interesses que não são os seus próprios. (STONE, 2013, p. 8)

A insegurança dos trabalhadores do conhecimento os leva a aceitar sobretrabalho não desejado e perigoso. (STONE, 2013, p. 9)

Se pensarmos no que os estudos empíricos nos informam sobre a natureza do trabalho nos países de capitalismo desenvolvido no momento atual, e muito especialmente no futuro não muito distante, teremos de admitir que as observações feitas por Brendan Stone são extremamente relevantes. É justamente nos locais onde o regime do capital emprega pessoas com elevado nível de qualificação profissional e elevado grau de envolvimento pessoal com sua atividade de trabalho, coisa que se tornará cada vez mais presente, que nos defrontaremos com as limitações inerentes à forma capitalista de organização da sociedade. As limitações do capitalismo ao desenvolvimento humano não aparecem na forma taylorista-fordista, é claro, pois aí não existe qualquer potencialidade de desenvolvimento humano, como ficou claro com os terríveis desdobramentos do uso do taylorismo pelo projeto socialista soviético. Como o capitalismo tratou de dar o merecido fim histórico ao taylorismofordismo, que, moribundo, só subsiste historicamente por meio da extremada mediocridade de experiências como as da Foxconn na China, então é imperioso que a análise crítica do capitalismo também enterre definitivamente esse desvio medíocre das forças produtivas capitalistas. É preciso localizar o debate crítico no lócus mais avançado da produção capitalista, onde se localizam justamente aqueles trabalhadores que aprenderam por sua experiência que um trabalho verdadeiramente livre, autônomo, impregnado de conteúdo, que permite o desenvolvimento das individualidades, é possível, pode ser visualizado e quase tocado com as mãos, mas é impedido de se concretizar pela permanência de uma forma 
atrasada de organização da sociedade, qual seja, o capitalismo. Lembrando conhecida observação contida no Manifesto comunista, o capitalismo se defrontará crescentemente com o fato de que cria civilização demais para sua demasiada estreiteza.

\section{Referências bibliográficas}

BRAVERMAN, H.- Trabalho e capital monopolista. Rio de Janeiro: Zahar, 1977.

BRYNJOLFSSON, E.; MCAFEE, A. A segunda era das máquinas: trabalho, progresso e prosperidade em uma época de tecnologias brilhantes. Rio de Janeiro: Alta Books, 2015

. Race agains the machine: how the digital revolution is

accelerating innovation, driving productivity, and irreversibly transforming employment and the economy. Lexington, Massachusetts: Digital Frontier Press, 2011.

CORIAT, B. Ciencia, tecnica y capital. Madri: H. Blume Ediciones, 1976. FREY, C. B.; OSBORNE, M. A. The future of employment: how susceptible are jobs to computerisation? Oxford Martin School: University of Oxford, 2013.

GORZ, A. -Divisão do trabalho, hierarquia e luta de classes. In: GORZ, A. et alii. Divisão do trabalho, tecnologia e modo de produção capitalista. Porto: Publicações Escorpião, 1974.

LEVY, F.; MURNANE, R. J. The new division of labor: how computers are creating the next job market. Nova York/Princeton/Oxford: Russell Sage Foundation/Princeton University Press, 2004.

LINHART, R. Lenine, os camponeses e Taylor. Lisboa: Iniciativas Editoriais, 1977.

MORAES NETO, B. R. Marx, Taylor, Ford: as forças produtivas em discussão. São Paulo: Editora Brasiliense, 1989.

- Século $X X$ e trabalho industrial: taylorismo/fordismo, ohnoísmo e automação em debate. São Paulo: Xamã Editora, 2003.

. Emprego e trabalho no início do século XXI: revisitando Keynes

e Marx. Caderno CRH, v. 27, n. 70, jan./abr. 2014.

PHELPS, E. S. Corporatism and Keynes: his Philosophy of Growth. In: PECCHI, L.; PIGA, G. (Ed.). Revisiting Keynes: economic possibilities for our grandchildren. Cambridge Massachusetts/London: The MIT Press, 2008.

SPENCER, D. A. Braverman and the contribution of labour process analysis to the critique of capitalist production - twenty-five years on. Work, Employment \& Society, 2000.

. The political economy of work. Londres/Nova York: Routledge, 2009. 
. Work in and beyond the second machine age: the politics of production and digital technologies. Work, Employment \& Society, June 2016. Disponível em: <http://eprints.whiterose.ac.uk/97294/>, acessado em 15 dez. 2018.

STONE, B. Will the "Knowledge economy" save us? Zero Anthropology, Nov. 2013. Disponível em: <htps://zeroanthropology.net/2013/11/11/willthe-knowledge-economy-save-us/>, acessado em 15 dez. 2018.

Como citar:

MORAES NETO, Benedito Rodrigues de. Processo de trabalho e relevância futura da crítica ao capitalismo. Verinotio - Revista on-line de Filosofia e Ciências Humanas, Rio das Ostras, v. 25, n. 1, pp. 11-27, abr. 2019.

Data de envio: 25 fev. 2019

Data de aceite: 28 mar. 2019 